Brit. J. industr. Med., 1953, 10, 195.

\title{
OCCUPATIONAL HEALTH PROBLEMS OF ENGLISH PAINTERS AND VARNISHERS IN 1825
}

\author{
BY
}

\author{
GEORGE ROSEN
}

\author{
From the School of Public Health, Columbia University, New York
}

The publication in 1832 of C. Turner Thackrah's work on "The Effects of Arts, Trades and Professions . . . on Health and Longevity" is justly considered a landmark in the development of occupational medicine in Great Britain. Intended " to excite the public attention to the subject," there is no doubt that this work achieved its purpose. In the medical literature Thackrah's monograph was, of course, not without antecedents. Heretofore, however, attention has not been called to any English non-medical publication dealing with specific problems of occupational health. The purpose of this essay is to direct attention to a small book, which appeared six years before Thackrah's work and dealt with the occupational health problems of one group of workers, namely, painters and varnishers.

In 1825, there appeared at London an anonymous publication entitled The Painter's and Varnisher's Pocket Manual. ... To which is added, Statement of the diseases and accidents to which painters and varnishers are peculiarly liable, with the simplest and best methods of prevention and remedy. This volume was apparently one of a series of practical pocket guides. Thus, the back cover lists two other titles, The Builder's Pocket Manual and The Cabinet Maker's Guide. The Manual measures $6 \frac{3}{8} \times 3 \frac{3}{4}$ inches and comprises 215 pages.

According to the anonymous author,

"The object of the Painter's and Varnisher's Manual is to give a clear, concise, and comprehensive view of the principal operations connected with the practice of those trades, and to embody in as little compass and as simple language as possible, the present state of knowledge in the arts of painting and varnishing, including all the information derived from the numerous recent discoveries in Chemistry" (p. 5).

\section{REFERENCE}

Thackrah, C. Turner (1832). The Effects of Arts, Trades, and Professions, and of Civic States and Habits of Living, on Health and Longevity, pp. 106, 108, 2nd ed., London.
"The numerous accidents and peculiar diseases" says the writer, "to which Painters and Varnishers are known to be liable in the exercise of their trade, have suggested to me the propriety of introducing a notice of the chief of these, with their general causes, pointing out the best means of prevention and remedy, and giving proper cautions against the injurious and injudicious attempts at cures too frequently made use of. For the information contained on this head, I am indebted to the kind assistance of a medical gentleman of extensive acquirements, and great experience" (pp. 7 and 8).

It has not been possible to ascertain the name of the " medical gentleman" who provided the information. Nevertheless, examination of Thackrah's book indicates that a number of physicians had observed and recorded various occupational health problems among painters and workers in related trades. Thus, he quotes a Dr. Alcock who reported that

"In an extensive lead factory in the vicinity of the metropolis [London], in which the colic peculiar to such places was formerly very prevalent, that disease has become so rare, that medical assistance has not, for some years past, been required. Many have supposed that the fumes of the lead induced the disease ; but the remedy was found by tracing the cause to a more direct source. Workmen are seldom very strict in regard to cleanliness. The probability of particles of the mineral being conveyed from the hands amongst the food was suggested, and an order enforced that before any of the workmen should leave the factory to go to meals, their hands should be thoroughly washed, and that nail brushes should be used to prevent any of the lead remaining where it was most likely to adhere. The success of this plan, under strict superintendence, has been complete"' (Thackrah, 1832). 
PANNTER'B AND VARNISHTMPS

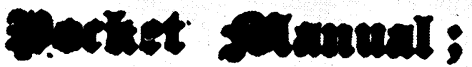

acrestive

IULBS AND INOTHUCTIOAS

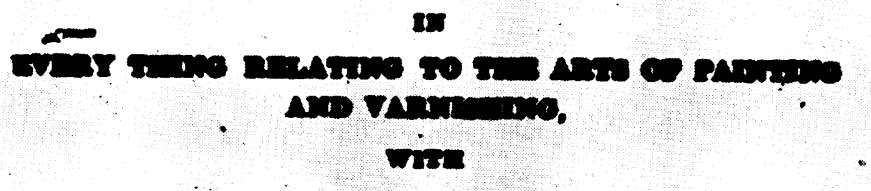

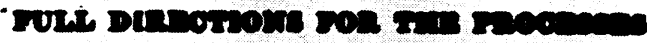

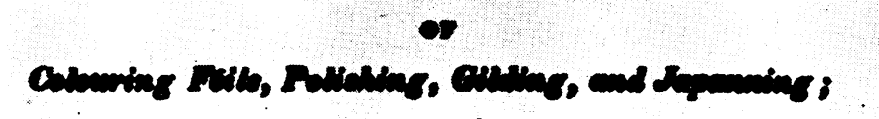

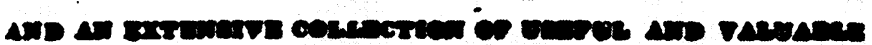

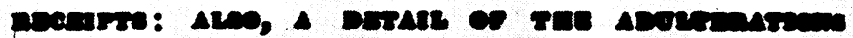

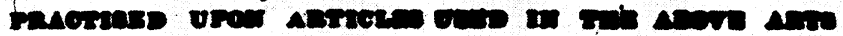

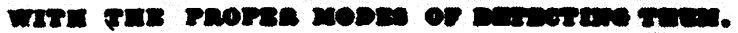

21 crited is aring,

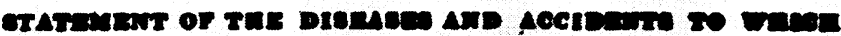

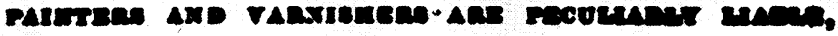

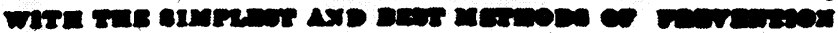
AND " RTMET.

\section{LONDON:}

\section{PRINTED FOR KNIGIY AND IAGt; - patzarnostrzinow,

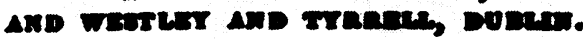

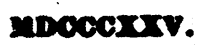

Thackrah (1832) also cites Robert Christison, the toxicologist, to the effect that London painters were reputed to suffer more from lead colic because the men worked longer hours and therefore did not have enough free time to cleanse themselves properly. Obviously, there was an interest in such matters among physicians who came in contact with them.

The health problems discussed in the Painter's and Varnisher's Pocket Manual are poisoning with lead, mercury, arsenic, and verdigris; nausea due to the inhalation of fumes arising from such substances as oil of turpentine ; and accidents, in particular, burns and scalds. Lead poisoning is discussed most fully under two headings : dry belly-ache and weakness of the wrists. In addition, there is a section devoted to general occupational hygiene. Here the emphasis is on temperance in the consumption of alcoholic beverages. Throughout, stress is placed on prevention (pp. 197-215).
This section is of interest also because it represents an attempt at the health education of a group of workers, and thus deserves a place in the history of health education as well as of occupational medicine. It is against this background that this early contribution to the occupational health problems of painters and varnishers is presented here in full.

\section{DISEASES AND ACCIDENTS TO WHICH PAINTERS AND VARNISHERS ARE PECULIARLY LIABLE}

The business of a Painter or Varnisher is generally, and not without reason, considered an unhealthy one. Many of the substances which he is necessarily in the habit of employing are of a nature to do injury both to the nerves and the inside, and great caution and care are required to prevent these from producing serious consequences. Much, however, of the mischief that is done arises from the want of proper precaution; the being ignorant of the symptoms of disorder, or want of due attention to them in the beginning; and more than all, the use of improper remedies, from the being unacquainted with those that ought to be used. I think, therefore, that I shall be rendering an acceptable service to the Painter and Varnisher by mentioning the principal diseases to which his occupation renders him more liable than persons differently employed, with the proper means of remedy; and I shall add some general observations on the best means of preventing, as far as possible, any serious attack of them.

\section{Dry Belly-ache}

This disease, the most common and the most dangerous to which Painters are liable, arises with them from breathing in the fumes, and handling the different preparations, of white lead. It is a violent species of cholic, and may be produced by other causes ; but when it proceeds from lead, it is always the most obstinate, and the most tedious and difficult of cure.

The first symptoms are, a pain at the pit of the stomach, gradually increasing, and proceeding downwards to the bowels ; it is particularly violent around the navel. The person is likewise affected with frequent belching, slight sickness at the stomach, continued thirst, a quick short pulse, a confinement of the bowels, and repeated attempts to obtain a stool without effect.

When some or all of these symptoms are experienced, a strong dose of castor oil should be immediately taken, and repeated till it opens the body freely. If it will not act, calomel pills must be taken 
in turn with the castor oil ; and should both these fail to purge effectually, a clyster must also be employed, composed of ten ounces of senna, and three grains of opium in solution. The warm bath, as well as warm fomentations, in flannel cloths, of the lower part of the stomach, are extremely serviceable in relieving the spasms; and should the symptoms continue, a blister applied to the abdomen may prove useful.

The person affected should be kept as quiet as possible both in body and mind; he should take no wine, spirits, malt-liquor, nor any kind of solid food, but should confine himself to broth diet, and copious draughts of weak diluting drinks, such as barley water.

Where the bowels are very obstinately confined, and the person is young and of a full habit, it may be advisable to begin with taking from him a quantity of blood, according to circumstances, in order to prevent inflammation.

I have not mentioned the strength of the doses to be employed as purgatives, because that must be determined by the constitution of the sick person, and the manner in which the medicines operate. In a general way, remember never to give too strong a dose at once, as it can always be repeated as often as may be found necessary.

If the remedies I have mentioned prove successful in removing the early symptoms of the dry bellyache, which will generally be the case, the person who has suffered, on returning to his work, should if possible entirely avoid, for some time, all parts of his business in which preparations of lead are employed. He should also, long after he may seem to feel quite well, keep to the light diet I have mentioned above, or he may bring on a relapse worse than the first attack of the disorder.

This disease is known in some parts of England by the name of the painter's colic. Few distempers grow more rapidly worse, and it is of the utmost importance to attend to its first symptoms, for if these are neglected, the most frightful consequences ensue. The violence of the pains increases beyond description; the outside of the belly feels pain at the slightest touch, and the muscles inside become wrapped into knots ; a difficulty of making water, sometimes amounting to almost a total stoppage, takes place, and the bowels are so contracted by spasm, as scarcely to admit a clyster. If these symptoms proceed, the spasms become more frequent and violent; and either the costiveness cannot be overcome, (in which case inflammation of the bowels succeeds, and the patient's death is certain), or if his life is saved, he generally remains a victim, in a greater or less degree, to the palsy.

I have mentioned these fatal circumstances, to show the necessity of immediately attending to the first appearances of this dangerous disorder. In an advanced state of it, I do not pretend to prescribe - the best medical assistance must immediately be obtained. The remedies I have recommended are only designed for that early stage of the distemper of which the symptoms have already been described. They may then be used with advantage, and if persevered in, will prevent the danger of severer suffering.

\section{Weakness of the Wrists}

This is a partial kind of palsy, which sometimes remains after the dry belly-ache is cured. In some cases, too, it comes on without any previous attack of that disorder, where the injury has been more owing to handling lead than breathing in its fumes.

Where this weakness of the wrists is experienced by a Painter, let him take, three or four times a day, a dose of nitrate of silver, of from one to three grains, according to the manner in which it may operate. Before taking each of these doses, he should also take some castor oil. If it purges him too violently, let a little opium be mixed with the dose, lest bloody stools should be brought on. It is better to give the nitrate of silver in solution than in a solid form.

Where the bowels are so weak as to make any strong purge dangerous, this weakness of the wrists has often been cured by rubbing a drachm of strong mercurial ointment upon them every night and morning, till the mouth became sore. Indeed this will always be found a useful application.

One of the best methods in the weakness of the wrists arising from the handling of lead, is, in addition to the taking of medicine, or the application of mercurial ointment, to make use of a splint, made something like a battledore, fastened under the forearm, and continued to the extremities of the fingers. This has, in many instances, restored the strength of the wrists, even where the weakness amounted to complete palsy.

I have already observed, that confirmed palsy may be the effect of a violent attack of the painter's colic. The remarks, however, which I made under that head apply here. I shall not venture to prescribe for that melancholy state of disease. My object is not to point out remedies for those extreme cases, but to suggest the best means of preventing them. 
EFFECTS OF POISONOUS SUBSTANCES USED IN PAINTING AND VARNISHING

These are principally lead, quicksilver, arsenic, and verdigris. Of the injurious effects of lead I have already spoken. Arsenic is found in some particular colours, particularly in orpiment and realgar, and this circumstance is a strong objection to the use of them. Quicksilver enters into the composition of various amalgams employed in lacquering and gilding. The poisonous properties of verdigris are well known.

It cannot be too strongly impressed upon the mind of the Painter or Varnisher, that mineral poisons of every description are as effectually taken into the system of the body by handling them or inhaling their fumes, as by actually swallowing them ; and that the consequences, though not so immediately fatal, are as certainly injurious. Care should therefore be taken not to handle them more than is absolutely necessary, and likewise, by keeping a thorough draught of air, and leaning as little as possible over such substances during their preparation, to avoid, as much as in your power, the breathing in the fumes arising from them.

But as you cannot entirely escape these, it will be well to know how to distinguish their respective characters. The effects of lead are sufficiently distinguished by the peculiar diseases it produces, which have been noticed before. Arsenic and quicksilver are attended with different consequences. When the former has found its way into the stomach, it will occasion a pricking and burning sensation, with thirst, and sometimes vomiting. A pain will likewise be felt in the bowels, but without producing purging. If, after using colours which contain a mixture of arsenic, you experience any of these symptoms, a little fresh charcoal, powdered fine, in small doses repeated, will be found very serviceable. An emetic should also be taken, and the body kept well open.

The fumes or handling of quicksilver produce, besides the symptoms mentioned in speaking of arsenic, salivation in greater or less degree, bad breath, griping pains in the stomach, and severe purging. White of egg dissolved in water and filtered, and diluted as circumstances require, is one of the best remedies when these symptoms are violent. A very good emetic in such cases, is one ounce of sub-carbonate of magnesia, dissolved in a pint of water ; a glassful of the mixture being taken every few minutes, at such intervals as are needful to produce vomiting.

Verdigris is readily distinguished by its nauseous and corroding effects upon the stomach. If you have reason to think you have suffered from the frequent use of this colour, common sugar, taken in such quantities as to open the bowels frequently, will be found the very best remedy.

I strongly recommend to every Painter and Varnisher, when engaged in any part of his business which requires him to employ a poisonous substance, whether lead or any other, the use of tobacco-I mean chewing it. It is the most powerful check to a substance acting to produce spasms by suspending the muscular action in the stomach. In short, tobacco possesses in this respect the advantages, without the danger, of opium, and has been found of the greatest service to persons in the trades above mentioned. At the same time, persons who use it for the purpose I have stated, should be careful not to indulge in the practice too freely, for the excessive chewing of tobacco would not only occasion a feeling of stupid languor, which would unfit a man for exertion, but might in time bring on a disease almost as much to be dreaded as the evils which it is intended to guard against.

\section{Nausea}

Oil of turpentine, burnt oils of several descriptions, and some other substances used in painting and varnishing, give out fumes which, though not a poisonous nature, are apt to occasion a slight sickness at the stomach, accompanied with a headache, and a fainting sensation, to persons whose nerves are not strong; and these effects are frequently felt by young people before they become accustomed to the business. In many cases, removing for a short time from the offensive fumes into a pure air, and drinking a very little spring water, will dissipate these feelings. If they return, some opening medicine or an emetic should be taken, which, if a foul stomach, as often happens, has been the cause, will remove it. But if you are a beginner in the business, and find yourself constantly affected in this manner on such occasions, I would advise you to try for some other occupation; for a person of decidedly weak nerves will be subject to constant ill health as a painter.

\section{Burns and Scalds}

In no business are these accidents more liable to occur to the persons engaged in it, than in of (sic) the Painter or Varnisher.

In all scalds and burns, it is of the first importance to apply a remedy at the instant. Spirits of wine or turpentine, applied at the moment, generally prevent the rising of blisters ; if it be rectified spirit it is so much the better. Spirit of wine or turpentine is 
decidedly the best immediate remedy when the skin is broke. If the violence or size of the burns or scalds render the application of the spirit in the common way too painful, cover the injured parts with pieces of bladder, softened by dipping them in warm water, and keep the outer surface constantly wetted with the spirit.

When the burn is considerable, fresh yolk of eggs (if spirit is not at hand) applied to it will relieve the pain, and forward the cure. A salve, composed of one part of yellow wax and three parts of olive oil, which you can easily make yourself, and carry about you in case of an accident, will likewise be extremely useful, if applied at the moment of its happening.

Scraped potatoe is very often applied to a scald or burn. Some have pronounced it a certain cure,others have called it injurious; both parties are wrong. The fact is, it does nothing towards curing the burn; but if applied at the first moment, it prevents its becoming worse, and relieves the pain. It is therefore very right to apply it, if no other remedy is near, till a better can be procured. Water, however, is almost always to be obtained, and in the absence of other remedies should instantly be had recourse to. The part or parts which have been injured should, without a moment's delay, be plunged into very cold water, or plentifully pumped upon, and an astonishingly rapid change from torture to ease will take place. After the immersion has continued a proper length of time, the parts injured should be covered with linen rags, continually kept wetted with water, and streams of air passed over them from time to time by a pair of bellows, till the person feels a freezing sensation.

Water is always serviceable in burns ; and where the skin is not broken, many eminent surgeons consider it as the best of remedies.

\section{GENERAL OBSERVATIONS}

I shall conclude this subject with a few general remarks, principally respecting the diet and manner of living of the Painter, on which indeed his exemption from the diseases which so severely affect many in his trade mainly depend.

He should avoid all acid drinks, such as cider, and effervescing liquors; and abstain as much as possible from sours, both in food and drink, even the use of vinegar; for acids have a particular tendency to combine with any portion of lead that he may have imbibed, and will act upon the stomach in a most injurious manner.

When a colicky feeling is experienced by the Painter, he often has recourse to a glass of raw spirits with the idea of obtaining relief. Now he cannot commit a greater error. This feeling indicates the commencement of that dangerous disorder, the dry belly-ache, and spirituous liquors will both bring it on more rapidly, and aggravate the symptoms. There is besides a vulgar, but most mistaken notion, that spirits, taken inwardly, are useful in guarding against fumes of lead, and other poisonous substances. And it is melancholy to see the number of persons engaged in the painting and varnishing line, who, from this false idea, are led to adopt the pernicious practice of drinking drams in the morning, and not unfrequently, from the hold this destructive habit gains upon them, at other times of the day too. Now, so far from this practice being serviceable, I can assure the dram-drinking Painter, that whenever he is attacked by that disease, so dangerous to those in his trade, he will find it rendered far more violent by his previous use of spirituous liquors, and more likely to terminate in inflammation or palsy. Ardent spirits, in a raw state, should never be touched by the Painter ; and when taken mixed, they should rather be weak than otherwise.

I have had frequent occasion to observe that Painters in general are partial to a great deal of solid and highly seasoned food. Now it will be perceived, that the disorder from which they have most to fear, and which is most common among them, is always attended by a confined state of the bowels, from which its principal danger arises. A painter who regards his health should always prefer such food as is light and easy of digestion ; and if he takes any solids, it should be in small quantities, and not frequently. For the same reason, though I do not condemn malt liquor to a Painter in good health, I should advise him not to take it in large quantities at a time, as it is heavy on the stomach. The lead, which he cannot avoid more or less imbibing, has a tendency to make him costive, and his business is not, like some others, accompanied with strong exercise to promote digestion.

I need scarcely remark on the advantages of cleanliness in his person to him, since the handling of preparations of lead is one of the injurious parts of his occupation.

In conclusion, let me once more impress upon him the importance and necessity of TEMPERANCE. The neglect of it in a workman of any other description, may bring him to sickness, must bring him to poverty; but the intemperate and drunken Painter or Varnisher makes the most rapid strides in his power to bring upon himself painful sickness, and, very often, premature death ! 